\title{
Comparative Analysis of COVID-19 Outbreak and Changes in Neurosurgical Emergency Patients
}

\author{
Min Ho Lee, Seu-Ryang Jang, Tae-Kyu Lee \\ Department of Neurosurgery, Uijeongbu St. Mary's Hospital, School of Medicine, The Catholic University of Korea, Seoul, Korea
}

Objective : COVID-19 has spread worldwide since the first case was reported in Wuhan, China, in December 2019. Our institution is a regional trauma and emergency center in the northern Gyeonggi Province. The changing trend of patient care in the emergency room of this hospital likely reflects the overall trend of patients in the area. In the present study, whether changes in the surrounding social environment following the outbreak of COVID-19 changed the incidence of neurosurgical emergency patients and whether differences in practice existed were investigated.

Methods : The overall trend was analyzed from January 2020 which is before the outbreak of COVID-19 to September 2020. To remove bias due to seasonal variation, the previous 2 year's records during the same period were reviewed and compared. Confirmed COVID-19 patients in the northern Gyeonggi Province were identified using data released by the government. And patients who came to the emergency department with head trauma and stroke were identified.

Results : Based on the present study results, the total number of neurosurgery emergency patients decreased over the study period. In the trauma patient group, the number of patients not involved in traffic accidents significantly decreased compared with patients involved in traffic accidents. Among the stroke cases, the rate of ischemic stroke was lower than hemorrhagic stroke, although a statistically significant difference was not observed. Meanwhile, an increase in the risk of mortality associated with trauma or stroke cases was not observed during the COVID-19 outbreak compared with the same time period in the previous year.

Conclusion : Due to the occurrence of COVID-19, non-essential activities have decreased and trauma cases not associated with traffic accidents appeared to decrease. Due to the decrease in overall activity, the number of stroke patients has also decreased. This trend is expected to continue even in the post-COVID-19 era, and accordingly, the results from the present study are relevant especially if the current situation continues.

Key Words : COVID-19 · Neurosurgery · Emergencies · Traumatic brain injury $\cdot$ Stroke.

\section{INTRODUCTION}

COVID-19 has spread worldwide since the first case was reported in Wuhan, China, in December 2019. The Republic of Korea reported its first confirmed case when a Chinese na- tional entered Korea from Wuhan on January 20, 2020. The Republic of Korea achieved some success in controlling COVID-19 by quarantining patients at the beginning of the outbreak. However, the outbreak is still not contained. The government of Korea implemented a three-level social distancing

- Received : February 27, 2021 •Revised : May 8, 2021 •Accepted : May 24, 2021

- Address for reprints : Tae-Kyu Lee

Department of Neurosurgery, Uijeongbu St. Mary's Hospital, School of Medicine, The Catholic University of Korea, 271 Cheonbo-ro, Uijeongbu 11765, Korea Tel : +82-31-820-3796, Fax : +82-31-820-5378, E-mail : magpie67@catholic.ac.kr, ORCID : https://orcid.org/0000-0002-4153-1292

This is an Open Access article distributed under the terms of the Creative Commons Attribution Non-Commercial License (http://creativecommons.org/licenses/by-nc/4.0) which permits unrestricted non-commercial use, distribution, and reproduction in any medium, provided the original work is properly cited. 
(SD) scheme (Table 1) ${ }^{13)}$. Until vaccines are developed, SD, maintaining personal hygiene, and wearing a mask are the only ways to prevent the spread of COVID-19. The virus has changed people's lifestyle and the practice of physicians. Due to limited resources, non-emergent care can be postponed but not emergency care.

Our institution is a regional trauma and emergency center in the northern Gyeonggi Province and is the only educational university hospital in the vicinity. The hospital manages primary emergency care for patients in this area and those transferred to our institution. Therefore, the changing trend of patient care in the emergency room of this hospital likely reflects the overall trend of patients in the area.

In the present study, whether changes in the surrounding social environment following the outbreak of COVID-19 changed the incidence of neurosurgical emergency patients and whether differences in practice existed were investigated.

\section{MATERIALS AND METHODS}

The study protocol was reviewed and approved by the Institutional Review Board of the Catholic University of Korea (UC21RISI0004), and adhered to the recommendations of the Declaration of Helsinki for biomedical research involving human subjects (1975). For this type of study formal consent is not required, and informed consent was waived by IRB.

In the present study, the influence of the outbreak of COVID-19 on the prevalence of patients from January 2020, before COVID-19 occurred in the region, to September 2020, was investigated. To remove bias due to seasonal variation, the previous 2 years records during the same period were reviewed and compared.

The overall trend was analyzed from January 2020 which is before the outbreak of COVID-19. When a confirmed case occurred in the hospital on March 31, 2020, the hospital stopped treating patients, including the emergency department, to quarantine and for epidemiological investigations. In

Table 1. Stepwise strategy of social distancing in Korea

\begin{tabular}{|c|c|c|c|}
\hline & Level 1 & Level 2 & Level 3 \\
\hline $\begin{array}{l}\text { No. of newly confirmed patients } \\
\text { (main focus on community) }\end{array}$ & Less than 50 & 50 to less than 100 & $\begin{array}{l}\text { 100-200 or more or doubling occurs } \\
\text { twice a week }\end{array}$ \\
\hline Gathering, meeting, venue & $\begin{array}{l}\text { Approved (recommendations for } \\
\text { compliance with quarantine } \\
\text { regulations) }\end{array}$ & $\begin{array}{l}\text { More than } 50 \text { people indoor and/or } \\
100 \text { people outdoor is prohibited }\end{array}$ & More than 10 people is prohibited \\
\hline $\begin{array}{l}\text { Kindergarten, elementary, middle, } \\
\text { and high school }\end{array}$ & $\begin{array}{l}\text { Remote class at school, } \\
\text { recommended to maintain 2/3 } \\
\text { density on campus }\end{array}$ & $\begin{array}{l}\text { Recommended to maintain the } \\
\text { majority of remote classes at } \\
\text { school, } 1 / 3 \text { of kindergarten, } \\
\text { elementary, and middle school, } \\
\text { and } 2 / 3 \text { of high school }\end{array}$ & $\begin{array}{l}\text { Different application depending on } \\
\text { the situation of remote classes or } \\
\text { closure, and national adjustment }\end{array}$ \\
\hline Public agencies and companies & $\begin{array}{l}\text { Minimization of density at work } \\
\text { through flexible, home-based } \\
\text { employment (1/3 of all employees) }\end{array}$ & $\begin{array}{l}\text { Restriction of the number of } \\
\text { employees through flexible, } \\
\text { home-based employment ( } 1 / 2 \text { of } \\
\text { the total number of employees) }\end{array}$ & $\begin{array}{l}\text { Recommendation to work from } \\
\text { home for all other employees }\end{array}$ \\
\hline
\end{tabular}

Table 2. Indication and classification definition of trauma and stroke cases

\begin{tabular}{lcc}
\hline \multicolumn{1}{c}{ Trauma cases } & \multicolumn{1}{c}{ Stroke cases } \\
\hline Total cases & S00-S09 (injuries to the head) & $\begin{array}{c}\text { 160-I68 (cerebrovascular diseases, excluding sequelae } \\
\text { of cerebrovascular disease) }\end{array}$ \\
Major cases & GCS $\leq 9$ or neurotrauma-related surgery (regardless of \\
GCS) & $\begin{array}{c}\text { NIHSS } \geq 10 \text { or endovascular intervention and surgical } \\
\text { treatment }\end{array}$ \\
Mortality cases & Died during hospitalization & Died during hospitalization \\
\hline
\end{tabular}

GCS : Glasgow coma scale, NIHSS : National Institutes of Health Stroke Scale 

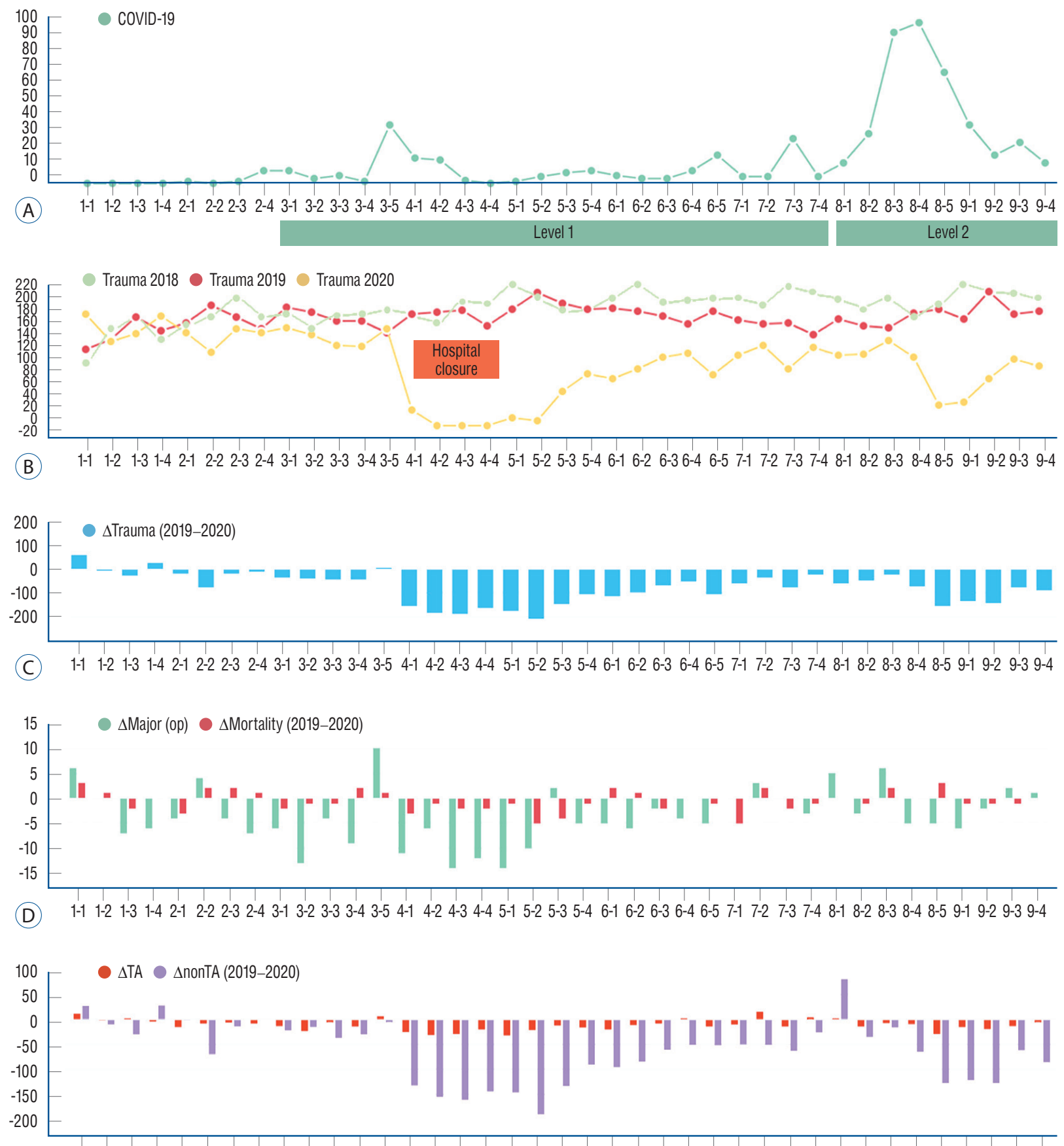

(E) 1-1 1-2 1-3 1-4 2-1 2-2 2-3 2-4 3-1 3-2 3-3 3-4 3-5 4-1 4-2 4-3 4-4 5-1 5-2 5-3 5-4 6-1 6-2 6-3 6-4 6-5 7-1 7-2 7-3 7-4 8-1 8-2 8-3 8-4 8-5 9-1 9-2 9-3 9-4

Fig. 1. Association between COVID-19 outbreak and head trauma patients. A : Weekly number of COVID-19 patients in northern Gyeonggi Province. B : Weekly number of head trauma patients compared between 2019 and 2020. C : Comparison of weekly increase or decrease in head trauma patients between 2019 and 2020. D : Comparison of weekly increase or decrease of major and mortality cases in head trauma patients between 2019 and $2020 . \mathrm{E}$ : Comparison of weekly increase or decrease in traffic accident-related cases and non-traffic accident-related cases in head trauma patients between 2019 and 2020. There was no noteworthy difference between the traumatic case of 2018 and 2019, the comparison of the increase and decrease bar graph was illustrated between 2019 and 2020 only.

order to objectively compare with the previous year, the cases were compared from May 2020 (after re-opening) thru Sep- tember 2020 .

Confirmed COVID-19 patients in the northern Gyeonggi 
Table 3. Demographics of traumatic injury patients pre-COVID-19 (May to September 2018 and May to September 2019) compared with duringCOVID-19 (May to September 2020)

\begin{tabular}{lcccc}
\hline & $\mathbf{2 0 1 8}$ & $\mathbf{2 0 1 9}$ & $\mathbf{2 0 2 0}$ & $\boldsymbol{p}$-value \\
\hline Total number of patients & 4228 & 4006 & 1961 & \\
Age & $29(1-108)$ & $29(1-104)$ & $38(1-101)$ & $<0.001^{*,+}$ \\
Sex, male & $2745(64.9)$ & $2588(64.6)$ & $1290(65.6)$ & $0.667^{\ddagger}$ \\
Major case & $247(5.8)$ & $223(5.6)$ & $167(8.5)$ & $<0.001^{+\neq}$ \\
Mortality case & $33(0.8)$ & $40(1.0)$ & $24(1.2)$ & $0.229^{\ddagger}$ \\
Traffic accident case & $670(15.8)$ & $559(14.6)$ & $331(16.9)$ & $0.063^{\ddagger, 5}$ \\
Non-traffic accident case & $3558(84.2)$ & $3266(85.4)$ & $1628(83.1)$ & \\
\hline
\end{tabular}

Values are presented as median (range) or number (\%). ${ }^{*}$ One way ANOVA with post-hoc Tukey test. ${ }^{\dagger}$ There were statistically significant between the year 2018 vs. 2020, and between the year 2019 vs. 2020, there were no statistically significant between the year 2018 vs. $2019 .{ }^{\ddagger}$ Chi-square test. ${ }^{~}$ There were statistically significant between the year 2019 vs. 2020, there were no statistically significant between the year 2018 vs. 2019 , and between the year 2018 and 2020

Province (Uijeongbu, Guri, Pocheon, Namyangju, Dongducheon, Yangju, and Yeoncheon) were identified using data released by the government. The number of confirmed patients with COVID-19 was reported daily on the website (www. gg.go.kr/).

During this period, patients who came to the emergency department with head trauma and stroke were identified. Data of all patients who were initially diagnosed with codes S00-S09 (injuries to the head) and I60-I68 (cerebrovascular diseases, excluding sequelae of cerebrovascular disease) based on International Classification of Disease-10 were extracted from electronic medical records. In the head trauma cases, a Glasgow coma scale (GCS) score of 9 or less and neurotraumarelated surgery (regardless of GCS score) were defined as major trauma cases. In the stroke cases, a National Institutes of Health Stroke Scale (NIHSS) score of 10 or more, and requirement for endovascular intervention and surgical treatment, were considered as major stroke cases. In the trauma and stroke case, all cases that were not able to survive after treatment, or even though surgical treatment was necessary but were not progressed due to refusal to treat, were also included in major cases. In addition, patients who died during hospitalization were identified and defined as mortality cases (Table 2).

Trauma patients were classified into patients involved and not involved in traffic accidents which included cars, motorcycles, and personal mobility vehicles, as well as drivers, passengers, and pedestrians. Stroke patients were classified into ischemic stroke patients and hemorrhagic stroke patients based on the disease code.

\section{Statistical analysis}

Patient demographic and clinical data were summarized using standard descriptive statistics and frequency tabulations. Chi-square test was used to evaluate the differences in the categorical variables and the One way ANOVA test with post-hoc Tukey test to evaluate differences in continuous variables between each years, from 2018 to 2020 . A $p$-value $<0.05$ was considered statistically significant. All statistical analyses were performed using R version 3.6 (https://cran.r-project.org/).

\section{RESULTS}

\section{COVID-19 outbreak}

The first confirmed COVID-19 case in Korea was on January 20, 2020. Since then, the government decided to increase its national alert level against the COVID-19 virus to "serious $^{\prime 8)}$. Afterward, under the supervision of the government and with active cooperation from the people, individuals maintained SD and quarantined. On June 28, 2020, the government implemented a three-level SD scheme (Table 1). In northern Gyeonggi Province, the first confirmed cases occurred on February 5, 2020. The World Health Organization declared the COVID-19 pandemic on February 23, 2020. When the first COVID-19 case was confirmed in our hospital on March 31, 2020, the hospital stopped treating patients including in the emergency departments, to quarantine and for 


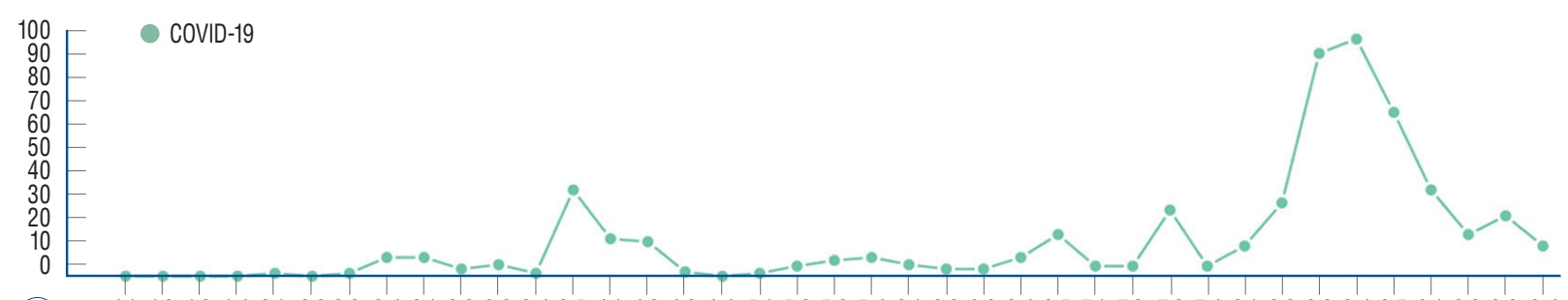

(A) 1-1 1-2 1-3 1-4 2-1 2-2 2-3 2-4 3-1 3-2 3-3 3-4 3-5 4-1 4-2 4-3 4-4 5-1 5-2 5-3 5-4 6-1 6-2 6-3 6-4 6-5 7-1 7-2 7-3 7-4 8-1 8-2 8-3 8-4 8-5 9-1 9-2 9-3 9-4

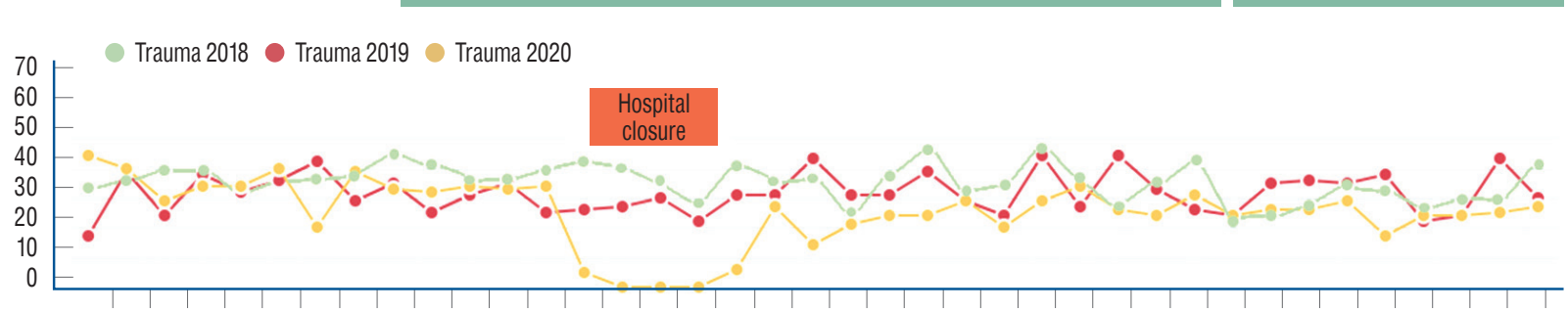

(B) 1-1 1-2 1-3 1-4 2-1 2-2 2-3 2-4 3-1 3-2 3-3 3-4 3-5 4-1 4-2 4-3 4-4 5-1 5-2 5-3 5-4 6-1 6-2 6-3 6-4 6-5 7-1 7-2 7-3 7-4 8-1 8-2 8-3 8-4 8-5 9-1 9-2 9-3 9-4

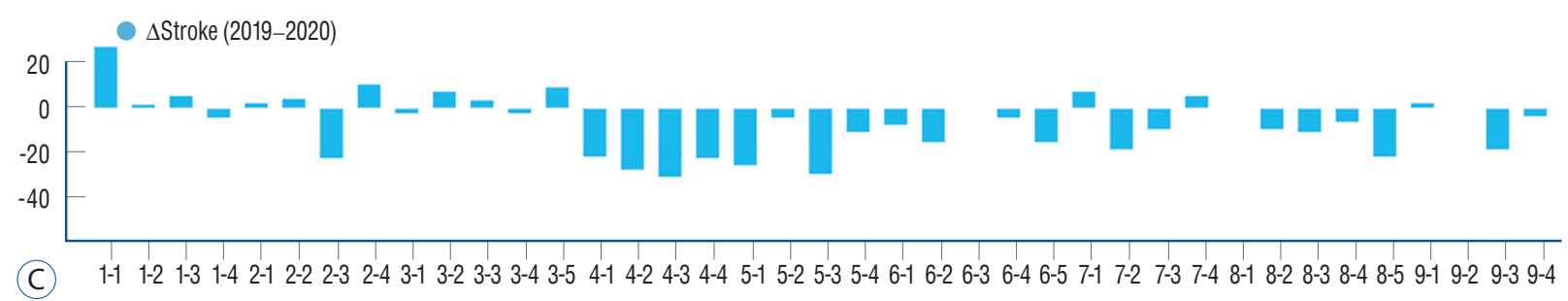

(C) 1-1 1-2 1-3 1-4 2-1 2-2 2-3 2-4 3-1 3-2 3-3 3-4 3-5 4-1 4-2 4-3 4-4 5-1 5-2 5-3 5-4 6-1 6-2 6-3 6-4 6-5 7-1 7-2 7-3 7-4 8-1 8-2 8-3 8-4 8-5 9-1 9-2 9-3 9-4
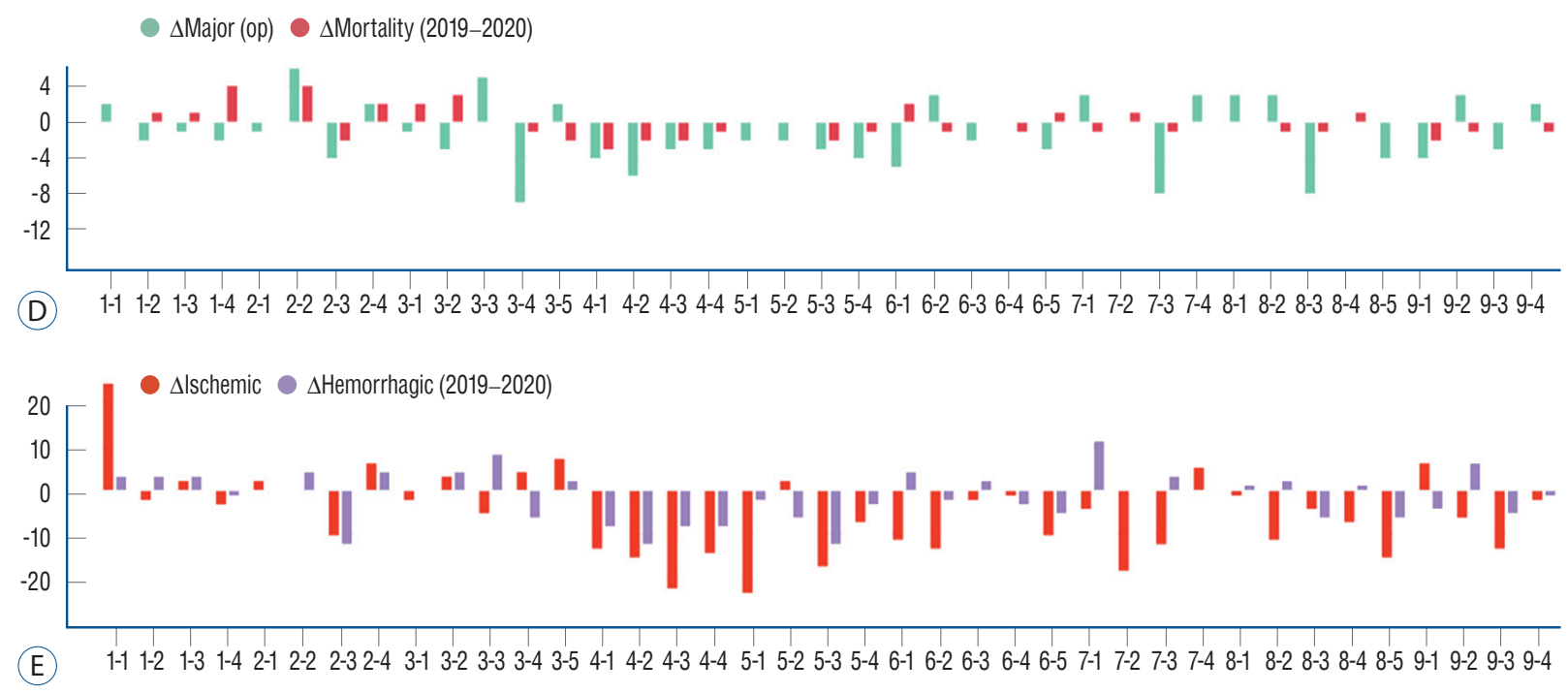

Fig. 2. Association between COVID-19 outbreak and stroke patients. A : Weekly number of COVID-19 patients in northern Gyeonggi Province. B : Weekly comparison of the number of stroke patients between 2019 and 2020. C : Comparison of weekly increase or decrease in stroke patients between 2019 and 2020. D : Comparison of weekly increase or decrease in major and mortality cases of stroke patients between 2019 and 2020. E: Weekly comparison of increase or decrease of ischemic and hemorrhagic cases in stroke patients between 2019 and 2020. There was no noteworthy difference between the stroke case of 2018 and 2019, the comparison of the increase and decrease bar graph was illustrated between 2019 and 2020 only.

epidemiological investigations, and temporarily closed for one month. The government maintained the first level of SD strategy and continued active quarantine measures, and the infec- tion in the region remained stable with less than 50 cases. As the number of patients began to rapidly increase in August 2020, the SD status was raised to the second level, and active 
Table 4. Demographics of stroke patients pre-COVID-19 (May to September 2018 and May to September 2019) compared with during-COVID-19 (May to September 2020)

\begin{tabular}{lcccc}
\hline & $\mathbf{2 0 1 8}$ & $\mathbf{2 0 1 9}$ & $\mathbf{2 0 2 0}$ & $\mathbf{p}$-value \\
\hline Total number of patients & 786 & 720 & 531 & \\
Age & $72(25-98)$ & $71(17-97)$ & $69(20-102)$ & $0.134^{*}$ \\
Sex & $438(55.7)$ & $388(53.9)$ & $269(50.7)$ & $0.194^{\dagger}$ \\
Major case & $81(10.3)$ & $121(16.8)$ & $93(17.5)$ & $<0.001^{\dagger, \neq}$ \\
Mortality case & $37(4.7)$ & $30(4.2)$ & $22(4.1)$ & $0.839^{\dagger}$ \\
Ischemic stroke case & $653(83.1)$ & $539(74.9)$ & $375(70.6)$ & $<0.001^{\dagger, \neq}$ \\
Hemorrhagic stroke case & $133(16.9)$ & $181(25.1)$ & $156(29.4)$ & \\
\hline
\end{tabular}

Values are presented as median (range) or number (\%). ${ }^{*}$ One way ANOVA with post-hoc Tukey test. ${ }^{\dagger}$ Chi-square test. ${ }^{*}$ There were statistical significance between the year 2018 vs.2019, and the year 2018 vs.2020, there was no statistical significance between the year 2019 vs. 2020

quarantine measures were implemented.

\section{Trauma cases}

When comparing COVID-19 patients (Fig. 1A) with trauma patients (Fig. 1B), the number of trauma patients decreased when the number of COVID-19 cases increased. In April 2020, the number of patients decreased due to hospital closure. In August 2020, the number of trauma patients decreased as the number of patients with COVID-19 rapidly increased and SD was raised to level 2 (Fig. 1C). Compared with the same period from the previous two years, the number of major surgical cases decreased but the proportion statistically increased (247 cases [5.8\%] in 2018, 223 cases [5.6\%] in 2019, and 167 cases [8.5\%] in 2020, $p<0.001)$. Conversely, significant difference was not observed in the ratio of mortality cases to the total number of patients (33 cases [0.8\%] in 2018, 40 cases [1.0\%] in 2019, and 24 cases [1.2\%] in 2020, $p=0.229$; Fig. 1D and Table 3). Notably, compared with the previous year, significant difference the proportion of patients not involved in traffic accidents significantly decreased from year 2019 to 2020 (3266 cases [85.4\%] in 2019 and 1628 cases [83.1\%] in 2020, $p=0.026$; Fig. $1 \mathrm{E}$ and Table 3).

\section{Stroke cases}

Regarding stroke cases, unlike traumatic cases, determining a relationship between the occurrence of COVID-19 cases and the occurrence of stroke was difficult (Fig. 2A-C). The total number of patients decreased. The proportion of major cases increased from 2018 to 2019, but there were no other changes after the outbreak of COVID-19 in 2020 (81 cases [10.3\%] in
2018, 121 cases [16.8\%] in 2019, and 93 cases [17.5\%] in 2020, $p<0.001$, statistical significance between 2018 vs. 2019). And statistically significant difference was not observed in mortality cases (37 cases [4.7\%] in 2018, 30 cases [4.2\%] in 2019, and 22 cases [4.1\%] in 2020, $p=0.839$; Fig. 2D). The proportion of ischemic cases decreased continuously compared with hemorrhagic cases from year 2018 to 2020 (653 cases [83.1\%] in 2018, 539 cases [74.9\%] in 2019, and 375 cases [70.6\%] in 2020; Fig. 2E and Table 4).

\section{DISCUSSION}

COVID-19 is causing an irreversible effect worldwide. This is an ongoing situation, and discussion on this subject is unfortunately expected to continue. The neurosurgery field may appear somewhat distant from COVID-19 but is inevitably affected, and the effects of COVID-19 on the prevalence of patients in our area was investigated in the present study.

Based on the present study results, the total number of neurosurgery emergency patients decreased over the study period. The Korean government has not yet implemented a lockdown policy. Therefore, the results are presumedly due to a decrease in personal activity and maintaining self-caution after the COVID-19 outbreak. In the trauma patient group, the number of patients not involved in traffic accidents significantly decreased compared with patients involved in traffic accidents. Because the policy did not restrict the movement of the population, apparently there was no significant difference in general life such as commuting. Conversely, the number of 
patients not involved in traffic accidents, including assaults or falls after drinking alcohol (a non-essential activity), decreased. Previously, traumatic brain injury-related emergency department visits and deaths steadily increased ${ }^{1)}$. This growing trend may be due to improved awareness of traumatic brain injury among providers and more accurate reporting and surveillance methods. However, the reason for the dramatically reduced number of cases, as in the present study, is likely due to COVID-19. In a Finland study ${ }^{11)}$, only the number of minor injuries were reduced and severe injuries were similar, however, the present study results also showed a statistically significant decrease in the number of major cases. This result is likely due to the decrease in overall activity. Furthermore, among the stroke cases, the rate of ischemic stroke was lower than hemorrhagic stroke, although statistically significant difference was not observed. In previous studies, hospital admissions due to transient ischemic attack, acute stroke, and acute coronary syndrome decreased during the COVID-19 pandemic ${ }^{3,4,6,12)}$. In a previous study, the number of treated aneurysmal subarachnoid hemorrhage and traumatic brain injury patients were lower during the pandemic ${ }^{12}$. In the Finland study ${ }^{11)}$, changes in the number of intensive care unit admissions or prognosis of patients with traumatic brain injury or subarachnoid hemorrhage during the pandemic reportedly also did not change. Ham et al. ${ }^{5)}$ presented their experience with spine surgery in a regional hospital. They reported that although the number of patients in the out-patients department and emergency department decreased, the actual number of surgery did not decrease.

In the present study, increase in risk of mortality associated with trauma or stroke cases was not observed during the COVID-19 outbreak compared with the same time period in the two previous years. In general, resource reallocation changes drastically $^{12}$. However, confirmed COVID-19 patients are not accepted at our institution; confirmed COVID-19 patients are transferred to other hospitals designated by the government. Therefore, changes at our hospital did not have to be made due to COVID-19. Although the number of patients was decreased and there were difficulties in social circumstances, the medical staff continued to provide the best treatment as before the COVID-19 pandemic.

The overall number of trauma and stroke patients was decreased compared with last year. Regarding trauma cases, the situation may differ depending on country and region. How- ever, trauma usually decreases when activity decreases ${ }^{7,14,15)}$. Regarding stroke cases, the situation may reportedly differ depending on climate ${ }^{10}$. In a previous meta-analysis, an increase in activity led to the prevention of ischemic stroke ${ }^{9)}$. The decrease in ischemic stroke observed in the present study is difficult to explain based on previously known risk factors for stroke $^{2}$. More investigation is needed on the continuous decrease in the proportion of ischemic stroke patients.

\section{Limitations}

Because this study was limited to one region, the results cannot be generalized nationally or globally. Lifestyles differ among regions and countries and government policies regarding COVID-19 are different in each country. And at the time the COVID-19 outbreak has not been resolved, the current results alone will be difficult to see as a final transition. After more data is collected in the near future, re-analysis of the differences after this difficult period is warranted.

\section{CONCLUSION}

Due to the occurrence of COVID-19, non-essential activities have decreased and trauma cases not associated with traffic accidents appeared to decrease. Due to the decrease in overall activity, the number of stroke patients has also decreased. Several vaccines against COVID-19 are now commercially available and vaccination has begun, and hopefully in the near future the virus will be under control. Plans should be made for the post-COVID-19 era. Society has already adapted to COVID-19 to some extent, and accordingly, the amount of activity has decreased as well as the number of visits to the hospital. This trend is expected to continue even in the post-COVID-19 era, and accordingly, the results from the present study are relevant especially if the current situation continues.

\section{CONFLICTS OF INTEREST}

No potential conflict of interest relevant to this article was reported. 


\section{INFORMED CONSENT}

This type of study does not require informed consent.

\section{AUTHOR CONTRIBUTIONS}

\author{
Conceptualization : MHL, TKL \\ Data curation : SRJ \\ Formal analysis : MHL \\ Methodology: TKL \\ Visualization : MHL, SRJ \\ Writing - original draft : MHL, SRJ \\ Writing - review \& editing : MHL, SRJ, TKL
}

\section{ORCID}

$\begin{array}{ll}\text { Min Ho Lee } & \text { https://orcid.org/0000-0001-6174-7579 } \\ \text { Seu-Ryang Jang } & \text { https://orcid.org/0000-0002-1111-7744 } \\ \text { Tae-Kyu Lee } & \text { https://orcid.org/0000-0002-4153-1292 }\end{array}$

\section{References}

1. Capizzi A, Woo J, Verduzco-Gutierrez M : Traumatic brain injury: an overview of epidemiology, pathophysiology, and medical management.

Med Clin North Am 104 : 213-238, 2020

2. Cui Q, Naikoo NA : Modifiable and non-modifiable risk factors in ischemic stroke: a meta-analysis. Afr Health Sci 19 : 2121-2129, 2019

3. De Filippo O, D'Ascenzo F, Angelini F, Bocchino PP, Conrotto F, Saglietto A, et al. : Reduced rate of hospital admissions for ACS during COVID-19 outbreak in northern Italy. N Engl J Med 383 : 88-89, 2020

4. Diegoli H, Magalhães PSC, Martins SCO, Moro CHC, França PHC, Safanelli J, et al. : Decrease in hospital admissions for transient ischemic attack, mild, and moderate stroke during the COVID-19 era. Stroke 51 : 2315-2321, 2020

5. Ham CH, Moon HJ, Kim JH, Park YK, Lee TH, Kwon WK : Coronavirus disease (COVID-19) outbreak and its impact on spinal daily practice : preliminary report from a single (regional) university hospital in republic of Korea. J Korean Neurosurg Soc 63 : 407-414, 2020

6. Hoyer C, Ebert A, Huttner HB, Puetz V, Kallmünzer B, Barlinn K, et al. : Acute stroke in times of the COVID-19 pandemic: a multicenter study. Stroke 51 : 2224-2227, 2020

7. Kamine $T H$, Rembisz A, Barron RJ, Baldwin C, Kromer M : Decrease in trauma admissions with COVID-19 pandemic. West J Emerg Med 21 : 819-822, 2020

8. Korean Society of Infectious Diseases; Korean Society of Pediatric Infectious Diseases; Korean Society of Epidemiology; Korean Society for Antimicrobial Therapy; Korean Society for Healthcare-associated Infection Control and Prevention; Korea Centers for Disease Control and Prevention : Report on the epidemiological features of coronavirus disease 2019 (COVID-19) outbreak in the Republic of Korea from January 19 to March 2, 2020. J Korean Med Sci 35 : e112, 2020

9. Kyu HH, Bachman VF, Alexander LT, Mumford JE, Afshin A, Estep K, et al. : Physical activity and risk of breast cancer, colon cancer, diabetes, ischemic heart disease, and ischemic stroke events: systematic review and dose-response meta-analysis for the global burden of disease study 2013. BMJ 354 : i3857, 2016

10. Li Y, Zhou Z, Chen N, He L, Zhou M : Seasonal variation in the occurrence of ischemic stroke: a meta-analysis. Environ Geochem Health $41: 2113-2130,2019$

11. Luostarinen T, Virta J, Satopää J, Bäcklund M, Kivisaari R, Korja M, et al. : Intensive care of traumatic brain injury and aneurysmal subarachnoid hemorrhage in Helsinki during the COVID-19 pandemic. Acta Neurochir (Wien) 162 : 2715-2724, 2020

12. Mathiesen T, Arraez M, Asser T, Balak N, Barazi S, Bernucci C, et al. : A snapshot of European neurosurgery December 2019 vs. March 2020: just before and during the COVID-19 pandemic. Acta Neurochir (Wien) $162:$ 2221-2233, 2020

13. Park IN, Yum HK : Stepwise strategy of social distancing in Korea. J Korean Med Sci 35 : e264, 2020

14. Sutherland M, McKenney M, Elkbuli A : Vehicle related injury patterns during the COVID-19 pandemic: what has changed? Am J Emerg Med 38 : 1710-1714, 2020

15. Taylor MS, Zelinkova V, Plancikova D, Melichova J, Sivco P, Rusnak M, et al. : Seasonal patterns of traumatic brain injury deaths due to trafficrelated incidents in the Slovak Republic. Traffic Inj Prev 21 : 55-59, 2020 